\title{
Nghiên cứu kinh nghiệm một số nước về quản lý nhà ở - Vận dụng vào địa bàn tỉnh Tiền Giang
}

\section{Housing Management: International experiences and application in Tien Giang Province}

\author{
Nguyễn Thị Thanh Phương ${ }^{1 *}$, Đoàn Minh Nguyệt ${ }^{2}$, Võ Kim Nhạn ${ }^{2}$ \\ ${ }^{1}$ Ban Quản lý dự án đầu tư xây dựng công trình dân dụng và công nghiệp tỉnh Tiền Giang, Việt Nam \\ ${ }^{2}$ Trường Đại học Tiền Giang, Việt Nam \\ *Tác giả liên hệ, Email: nguyenthithanhphuong2005@gmail.com
}

THÔNG TIN

DOI: $10.46223 / \mathrm{HCMCOUJS}$.

proc.vi.16.1.1856.2021

Ngày nhận: 7/3/2021

Ngày nhận lại: 31/3/2021

Duyệt đăng: 9/4/2021

Tù khóa:

quản lý nhà ở, chính sách, lý thuyết nhà ở

Key words:

housing management, housing policy

\section{TÓM TẮT}

Bài báo này nhằm thể hiện tính cấp thiết trong nghiên cứu chính sách nhà ở cho người dân vì đó là công cụ để tạo điều kiện cho người dân an tâm về chỗ ở và góp phần tăng trưởng nền kinh tế. Bên cạnh đó, nhóm tác giả lược khảo lý thuyết về nhà ở, cũng như nghiên cứu kinh nghiệm quản lý nhà ở của một số nước. Từ đó, nhóm tác giả đề xuất một số gợi ý chính sách nhằm sử dụng tối ưu các nguồn lực hiện có để phát triển và quản lý nhà ở đạt hiệu quả trên địa bàn tỉnh Tiền Giang.

ABSTRACT
The paper focuses on the necessity of housing management
policies in creating basic conditions for people about
accommodation and contributing to economic growth. In
addition, the authors review the theory and experiences of
housing management policy in some countries. In addition, the
authors intend to propose some suggestions for effective
housing management in the case of Tien Giang province.

\section{Giới thiệu}

Ở một số nước, quá trình đô thị hoá đã được sử dụng như một giải pháp để thúc đẩy tăng trưởng kinh tế và xoá đói giảm nghèo. Việt Nam muốn duy trì tỷ lệ tăng trưởng cao thì việc tiếp tục hỗ trợ quá trình đô thị hoá đóng góp tỷ lệ đáng kể vào việc tạo việc làm và tăng trưởng kinh tế, sẽ là một biện pháp quan trọng. Sự thay đổi cấu trúc này sẽ khiến dân số và nhu cầu nhà ở gia tăng ở các thành phố, theo đó các giải pháp về nhà ở giá hợp lý, chất lượng tốt, trong những khu dân cư có dịch vụ tốt sẽ hết sức cần thiết. Đây chính là thời điểm tốt để các địa phương tập trung nỗ lực vào lĩnh vực nhà ở. Nước ta đã trải qua nhiều giai đoạn khác nhau về chính sách nhà ở. Trước năm 1986, lĩnh vực nhà ở chính thức của Việt Nam được quản lý thông qua chế độ kế hoạch hoá tập trung, nhưng kể từ sau đổi mới đã theo định hướng thị trường, khiến cho khu vực này phát triển, đặc biệt ở phân khúc cao cấp cả về cung lẫn cầu. Mặt khác, các hộ nghèo và cận nghèo lại khó tiếp cận được với nhà ở hơn. Luật Nhà ở (2014) đã tạo khuôn khổ pháp lý cho việc cải cách lĩnh vực nhà ở như chính sách hỗ trợ nhà ở cho người dân tự xây và sự tham gia chủ động của tư nhân, giải quyết vấn đề thiếu hụt nhà ở cho thuê với giá cả hợp lý cũng như đáp ứng nhu cầu cao của các nhóm người có thu nhập thấp, đặc biệt là công nhân khu công nghiệp. Mặc dù liên tục tăng trưởng về kinh tế, nước ta vẫn còn tình trạng thiếu hụt lớn về nhà ở đảm bảo chất 
lượng. Gia tăng dân số và đô thị hoá đã khó khăn cho mọi người dân được tiếp cận với nhà ở an toàn với giá hợp lý. Nhu cầu mới về nhà ở đã, đang và sẽ tiếp tục tập trung ở một vài thành phố lớn và các khu công nghiệp. Nguồn cung hiện tại chủ yếu phụ thuộc vào các giải pháp nhà ở tự xây. Đa số các sản phẩm nhà ở là do các doanh nghiệp đầu tư bất động sản quy mô nhỏ, các chủ thầu xây dựng nhỏ lẻ và bản thân các hộ gia đình cung cấp. Tuy nhiên, các hộ gia đình thu nhập thấp và trung bình vẫn phải đối mặt với nhiều khó khăn trong việc nắm bắt nguồn lực cần thiết để có được một căn nhà tự xây dựng khang trang. Thứ nhất, việc tiếp cận với đất đai được công nhận chính thức để tự xây nhà thường nằm ngoài khả năng chi trả do thủ tục tốn kém và rườm rà để có được quyền sử dụng chính thức. Thứ hai, khả năng tiếp cận tài chính là một cản trở với nhiều hộ gia đình thu nhập thấp và lao động phi chính thức phần lớn là do mức độ bao phủ của dịch vụ tài chính còn thấp. Năng lực kỹ thuật để đảm bảo chất lượng công trình cũng là một rào cản nhất định. Ngoài ra, một số luật lệ, thủ tục hành chính nhất định đã khiến các hộ gia đình rơi vào tình trạng không được công nhận chính thức, ví dụ như quy định về diện tích tối thiểu và các yêu cầu về cơ sở hạ tầng. Nước ta đã có nhiều chính sách về nhà ở để có nhiều sự linh hoạt hơn, chú trọng hơn vào nhu cầu của khu vực này như cho phép miễn giấy phép xây dựng đối với các dự án nhỏ, điều này thể hiện sự quan tâm, ủng hộ của nhà nước đối với khu vực này.

Vì vậy, nghiên cứu về quản lý nhu cầu nhà ở trong dân cư hiện nay là cấp thiết và cần được các cấp, ngành quan tâm vì quản lý nhà ở tốt là giải pháp giúp nước ta nói chung và tỉnh Tiền Giang nói riêng đạt được mục tiêu nâng cao chất lượng sống của người dân trong quá trình hội nhập quốc tế sâu rộng hiện nay

\section{Cơ sở lý thuyết}

\subsection{Các khái niệm về nhà ở}

Nhà ở được hiểu là công trình xây dựng có mái, có tường vách được sử dụng làm chỗ ở, thường cùng với gia đình (Tù điển Tiếng Việt). Nhà ở là công trình xây dựng với mục đích sử dụng là để ở và phục vụ các nhu cầu sinh hoạt của cá nhân, hộ gia đình. Phân loại theo mục đích sử dụng thì nhà ở bao gồm: nhà ở riêng lẻ, nhà chung cư, nhà ở thương mại, nhà ở công vụ, nhà ở để phục vụ tái định cư, nhà ở xã hội. Cụ thể: Nhà ở riêng lẻ (gồm: biệt thự, nhà ở liền kề, nhà ở độc lập) là nhà ở thuộc quyền sử dụng hợp pháp của cá nhân, hộ gia đình, tổ chức được xây dựng trên đất được ghi nhận có mục đích sử dụng là đất ở (đất thổ cư).Nhà chung cư là nhà ở có cả phần sở hữu riêng và chung, có nhiều hơn một tầng, nhiều căn hộ, có lối đi, cầu thang và hệ thống hạ tầng sử dụng chung cho các hộ dân cư. Chung cư được chia làm hai loại dựa vào mục đích sử dụng là để ở và sử dụng hỗn hợp vừa để ở,vừa để kinh doanh. Nhà ở thương mại là nhà ở được đầu tư xây dựng nhằm mục đích bán hoặc cho thuê lâu dàitheo cơ chế thị trường. Nhà ở công vụ là nhà ở chỉ dành cho các đối tượng thuộc danh sách đang làm việc hay thực hiện công việc, đảm nhiệm chức vụ mà nhà nước giao cho được ưu tiên thuê để ở. Nhà ở để phục vụ tái định cư là nhà ở do Nhà nước hỗ trợ tái định cư cho các cá nhân, hộ gia đình khi bị thu hồi giải phóng mặt bằng. Nhà ở xã hội là nhà ở mà Nhà nước dành cho các trường hợp thuộc chính sách hỗ trợ (ví dụ như: người có công với cách mạng; gia đình thuộc hộ nghèo, cận nghèo,...).Phân loại theo quản lý chất lượng công trình xây dựng thì nhà ở được chia làm nhà chung cư và nhà riêng lẻ. Nhà ở riêng lẻ gồm: biệt thự, nhà cấp I, nhà cấp II, nhà cấp III, nhà cấp IV, nhà tạm còn biệt thự thì được đánh giá từ hạng 1 đến hạng 4 (Quốc hội, 2014).

\subsection{Lý thuyết về nhà ở}

Dựa theo nghiên cứu của Kemeny (1992), lý thuyết về nhà ở của Clapham (2018) thể hiện rằng bất kể quy mô can thiệp, Chính phủ và các cơ quan Chính phủ có số loại cơ chế mà họ 
có thể sử dụng trong việc quản lý nhà ở của họ, bao gồm như sau:

Đầu tiên là quy định. Đây có thể liên quan đến việc thiết lập các giới hạn hành động của các chủ thể tư nhân và thể chế hóa xã hội thực tiễn trên thị trường nhà ở. Một ví dụ phổ biến là quy định của tư nhân lĩnh vực thuê có thể liên quan đến việc kiểm soát giá thuê, hạn chế hoạt động cho thuê và cung cấp bảo đảm về quyền hưởng dụng cho người thuê. Nhưng quy định cũng có thể liên quan đến quy định của hành vi của các đối tượng có liên quan. Ví dụ có thể đang diễn ra trách nhiệm sở hữu bằng cách chuyển ra khỏi nhà ở xã hội hoặc nhận việc làm hoặc tăng giờ làm, hoặc chuyển đến chỗ ở nhỏ hơn..

Hình thức thứ hai là cung cấp trục tiếp. Điều này có thể có nghĩa là quốc gia hoặc cơ quan nhà nước trực tiếp xây dựng nhà ở để bán hoặc thông thường hơn là cho thuê. Chính phủ có thể không thực hiện tất cả các giai đoạn phát triển nhà ở mà nó có thể khoán công việc xây dựng thực tế cho nhà thầu tư nhân. Ví dụ về cung cấp trực tiếp thường gặp nhất là cung cấp nhà ở xã hội, nhưng nhà nước có thể cung cấp các dịch vụ nhà ở khác, chẳng hạn như chỗ ở và hỗ trợ cho người vô gia cư.

Hình thức can thiệp thứ ba là thông qua cung cấp tài chính hoạc trợ cấp. Chính phủ có thể cung cấp các khoản tài trợ hoặc cho vay sẵn có cho các cá nhân hoặc tổ chức để đạt được các mục tiêu cụ thể. Các khoản thanh toán cho cá nhân có thể cho phép họ đủ khả năng. Nếu không, họ sẽ không thể thay đổi nhận thức, thái độ và hành vi đối với việc sở hữu hoặc sử dụng nhà ở, ví dụ, giảm sử dụng năng lượng trong nhà hoặc sửa chữa nhà. Các khoản tài trợ cho các tổ chức như nhà xây dựng và nhà phát triển tư nhân có thể được thiết kế để tăng nguồn cung nhà ở hoặc thay đổi bản chất của nó, chẳng hạn như cải thiện tiêu chuẩn về hiệu quả năng lượng.

Hình thức can thiệp thứ tư là thông qua việc cung cấp thông tin hoặc hướng dẫn.

Có sự bất cân xứng về thông tin giữa những người tham gia mua và bán những ngôi nhà. Do đó, Chính phủ có thể hành động để cung cấp một số thông tin này hoặc khuyến khích hoặc buộc một bên khác cung cấp nó. Thông tin và hướng dẫn cũng có thể cung cấp cho những cá nhân dễ bị tổn thương, những người có thể gặp vấn đề, có nghĩa là họ có thể yêu cầu trợ giúp từ công tác xã hội hoặc các chuyên gia khác để có thể tham gia thành công trong quá trình nhà ở.

Hình thức can thiệp thứ năm là thiết lập các mô hình trách nhiệm giải trình cho các tổ chức trong nhà ở. Nói cách khác, Chính phủ có thể xác định các mối quan hệ giữa các bên liên quan đến nhà ở. Một ví dụ có thể là đặt mục tiêu hoặc giám sát các thủ tục để đảm bảo rằng các cơ quan quản lý nhà ở xã hội phải tham khảo ý kiến của người thuê.

Thứ sáu, các chính phủ thuoòng tích cưc trong lĩnh vục thảo luận xung quanh vấn đề nhà $o ̛$. Nghĩa là thiết lập các điều khoản thảo luận và tranh luận và xác định vấn đề liên quan đến chính sách nhà ở. Ví dụ, các quốc gia khác nhau về thái độ đối với tình trạng vô gia cư, với một số người coi đó là kết quả của sự không hoàn hảo trong thị trường nhà ở và những người khác như một thất bại cá nhân của chính những người vô gia cư. Cho dù là diễn ngôn nào chiếm ưu thế và được chấp nhận bởi Chính phủ định khungtranh luận về vấn đề này và các hành động được thực hiện để giải quyết nó. Một số chính sách sẽ có yếu tố biểu tượng mạnh mẽ trong mối quan hệ với niềm tin chính trị và hệ tư tưởng. Ví dụ, nghề nghiệp của chủ sở hữu đôi khi được cho là biểu tượng cho tầm quan trọng của tư nhân, quyền tài sản và cho vay, tính hợp pháp đối với các quan hệ thị trường và hạn chế sự can thiệp.

Thứ bảy là không can thiệp. Sau cuộc tranh luận về tầm quan trọng của việc không ra quyết định như một hình thức quyền lực được Lukes (1974), Doling (1997) lập luận rằng lựa chọn không can thiệp vào thị trường nói chung hoặc các trường hợp cụ thể là một chính sách nhà ở theo đúng nghĩa của nó sẽ có thể xác định kết quả.Căn cứ vào lý thuyết nhà ở mà Chính phủ 
các nước sử dụng, ưu tiên cách thức can thiệp nào để quản lý nhà ở tùy thuộc vào thể chế, nguồn lực, đối tượng thụ hưởng,...được cho là phù hợp nhất trong từng giai đoạn nhất định.

\section{Kinh nghiệm một số nước đối với việc quản lý nhà ở}

\subsection{Trung Quốc}

Mua nhà tại các thành phố đã trở thành một xu hướng mới tại Trung Quốc. Sử dụng khảo sát quốc gia gần đây có tên là Khảo sát tác động dân số di cư quốc gia (NMPDMS) để khám phá các yếu tố quyết định về nhà ở của người dân cho thấy người dân mua nhà ở thành thị và có xu hướng đầu tư mua nhà ở quê nhà có mối quan hệ chặt chẽ với việc sở hữu của người dân (Wang, Liu, \& Ming, 2020b). Ngoài ra, mô hình dựa trên quyền chọn (Foster \& Order, 1984) chứng tỏ giá nhà giảm dẫn đến nhiều vụ vỡ nợ hơn và rủi ro tín dụng ngày càng tăng. Trong khi đó, rủi ro tín dụng tăng cao có khả năng đi kèm với giá nhà tăng. Giá nhà tăng không ảnh hưởng đến rủi ro tín dụng. Nghiên cứu của Su, Cai, Qin, Tao, và Umar (2020) nhận thấy việc mở rộng tín dụng của các ngân hàng có thể không hợp lý dẫn đến việc tích tụ rủi ro tín dụng. Chính sách tín dụng thắt chặt và lãi suất vay cao đã kích thích giá nhà giảm. Việc các ngân hàng tăng cường kiểm tra tín dụng cá nhân để ngăn chặn các khoản cho vay đầu cơ là điều cần thiết. Các cơ quan quản lý nên tính đến tác động đối với tín dụng ngân hàng khi họ xây dựng chính sách kiểm soát giá nhà.

Mặc dù Trung Quốc đã chứng kiến sự gia tăng đáng kể về tài sản nhà ở và tổng tài sản hộ gia đình trong thời gian gần đây. Trong nhiều thập kỷ ở cả thành thị và nông thôn, sự bất bình đẳng về nhà ở đã gia tăng đáng kể và sự chênh lệch giữa thành thị và nông thôn vẫn còn đáng kể (Wang, Li, Huang, Yi, \& Ren, 2020a).Chính sự bất bình đẳng xã hội gây ra bởi khả năng tiếp cận giáo dục là phổ biến và gây lo ngại cho các nhà hoạch định chính sách quản lý nhà ở ở Trung Quốc. Các nhà quản lý nhà ở Trung Quốc thực hiện chính sách cho thuê nhà theo chuỗi thời gian, họ đánh giá chất lượng trường học có tác động đáng kể đến giá thuê nhà sau khi chính sách nhà ở mới này được áp dụng. Hơn nữa, nhà ở giá thuê trong các khu chất lượng cao cao hơn đáng kể so với giá thuê trong trường bình thường.

\subsection{Singapore}

Trong các nước Châu Á, Singapore được xem như là một quốc gia có mô hình giải quyết nhà ở thành công nhất. Mô hình này dựa trên chương trình nhà ở công cộng mà cơ quan điều hành chương trình này là Hội đồng phát triển nhà ở Singapore (HDB) được thành lập vào tháng 2/1960 (Teo, Devadoss, \& Pan, 2006). Mỗi năm HDB nhận được từ ngân sách Nhà nước bình quân 1.2 tỷ USD cho xây dựng nhà ở xã hội. HDB đã xây dựng được trên 800.000 căn hộ các loại với các tiện nghi cần thiết cho người ở theo từng đối tượng. Hiện nay trên $90 \%$ dân số sống ở các chung cư cao tầng trong đô thị trong đó $81 \%$ mua nhà của HDB bằng hình thức vay tiền trả dần với lãi suất căn cứ vào tình hình cụ thể.

\section{3. Ân $Đ \hat{o}$}

Nhà nước không quan tâm đến chính sách nhà ở như Ân Độ, hầu hết thị trường nhà ở đều do tư nhân kiểm soát, không có chính sách hỗ trợ của Nhà nước. Để đạt lợi nhuận cao, các chủ đầu tư đều tập trung xây dựng nhà ở đắt tiền, chỉ những người có thu nhập cao mới có thể mua được, người có thu nhập thấp thường phải sống trong các nhà không đủ tiêu chuẩn.Các bên liên quan đến chính sách nhà ở như nhà hoạch định chính sách, kiến trúc sư, hợp tác xã quản lý và người lao động là hai thế giới khác nhau. Khoảng cách này gợi lên nhu cầu về một khuôn khổ hệ thống hơn cho cách tiếp cận có sự tham gia tạo ra bất bình đẳng về sở hữu nhà ở (Gopalan \& Venkataraman, 2015).

\section{Kết luận và gọii ý chính sách}




\subsection{Kết luận}

Bài báo "Nghiên cứu kinh nghiệm một số nước đối với việc quản lý nhà ở - vận dụng trường hợp địa bàn tỉnh Tiền Giang” với mục đích là dựa trên nền tảng lý thuyết về quản lý nhà ở và các nghiên cứu có liên quan cả ở trong và ngoài nước trước đây, nhómtác giả đã xác định định hướng, gợi ý một số gợi ý chính sách có thể tham khảo áp dụng cho công tác quản lý nhà ở trên địa bàn tỉnh Tiền Giang trong thầm quyền là cơ quan quản lý cấp tỉnh trực thuộc trung ương.

\subsection{Gợi ý chính sách}

- Cung cấp thông tin về các văn bản có liên quan đến nhà ở, quy hoạch hệ thống nhà và đất ở, cập nhật cho người dân kịp thời, đáng tin cậy thông qua các công cụ công nghệ thông tin như website chính thức, email, điện thoại đường dây nóng của bộ phận phụ trách thông tin để hỗ trợ, cung cấp thông tin đến người dân kịp thời.

- Chính sách phát triển nhà ở đảm bảo phù hợp quy hoạch xây dựng của Tỉnh theo hướng khai thác tối đa hiệu quả của tiện ích của nhà ở theo hướng hiện đại, tiết kiệm năng lượng và diện tích đất ở, phát triển bền vững.

- Cùng với đó,kêu gọi đầu tư theo hướng phát triển đa dạng các loại hình nhà ở, tạo hình ảnh đa dạng, năng động và hiện đại như nhà ở chung cư, khu dân cư tập trung,...

- Bố trí quỹ đất và huy động nguồn vốn để phát triển nhà ở xã hội cho đối tượng gia đình có thu nhập thấp theo thực hiện Chỉ thị số 03/CT - TTg ngày 25/1/2017của Thủ tướng Chính phủ về đẩy mạnh phát triển và quản lý nhà ở xã hội.

- Tăng cường công tác cải cách thủ tục hành chính; đẩy nhanh tiến độ lập, thẩm định và phê duyệt quy hoạch phân khu, quy hoạch chi tiết trên cơ sở quy hoạch chung Tỉnh đã được phê duyệt; xem xét, thành lập tổ công tác liên ngành để khẩn trương hướng dẫn, tháo gỡ những khó khăn, vướng mắc đối với các dự án, giải quyết tranh chấp, khiếu nại kéo dài trong dân trên địa bàn đang bị ách tắc, tạm dừng.

\section{Tài liệu tham khảo}

Clapham, D. (2018). Housing theory, housing research and housing policy. Housing, Theory and Society, 35(2), 163-177.

Doling, J. (1997). Comparative housing policy: Government and housing in advanced industrialized countries. New York, NY: Macmillan.

Foster, C., \& Order, R. V. (1984). An option based model of mortgage default. Housing Finance Review, 3(4), 351-372.

Gopalan, K., \& Venkataraman, M. (2015). Affordable housing: Policy and practice in India. IIMB Management Review, 27(2), 129-140.

Kemeny, J. (1992). Housing and social theory. London, UK: Routledge.

Lukes, S. (1974). Power: A radical view. London, UK: Macmillan

Quốc hội. (2014). Luật nhà ở [Housing law]. Retrieved October 10, 2019, from https://thuvienphapluat.vn/van-ban/Bat-dong-san/Luat-Nha-o-2014-259721.aspx

Su, C. W., Cai, X. Y., Qin, M., Tao, R., \& Umar, M. (2020). Can bank credit withstand falling house price in China? International Review of Economics \& Finance, 71, 257-267.

Teo, T. S., Devadoss, P., \& Pan, S. L. (2006). Towards a holistic perspective of Customer 
Relationship Management (CRM) implementation: A case study of the housing and development board, Singapore. Decision Support Systems, 42(3), 1613-1627.

Wang, Y., Li, Y., Huang, Y., Yi, C., \& Ren, J. (2020a). Housing wealth inequality in China: An urban-rural comparison. Cities, 96, 1-8.

Wang, Z., Liu, J., \& Ming, J. (2020b). Owned a house in an urban destination or made housing investments in the hometown? Determinants of rural migrants' housing attainments in China. Housing Policy Debate, 30(3), 348-369. 